\title{
Styrene-Divinylbenzene Copolymers. II. The Conservation of Porosity in Styrene-Divinylbenzene Copolymer Matrices and Derived Ion-Exchange
} Resins

\author{
H. HILGEN, G. J. DE JONG, and W. L. SEDEREL, Akzo-Zout-Chemie \\ Research, Hengelo and Polymer Division, Department of Chemical \\ Technology, Twente University of Technology, Enschede, The Netherlands
}

\section{Synopsis}

The collapse of pores in styrene-divinylbenzene copolymers and corresponding ion-exchange resins was studied during the removal of solvating liquids. The process can be followed in a most simple way by measuring the volume of the bead-shaped copolymers upon drying. Other parameters observed during drying were the apparent density and incidently the internal surface. The collapse of pores is considered to be a result of cohesional forces when solvated polymer chains are approaching each other by loss of solvent. The effect will thus be more pronounced in gel-type networks than in porous ones. In porous networks, the effect will be stronger in smaller pores than in larger ones. It is shown that crosslinks, increasing the rigidity of the structures, will favor the conservation of porosity. In ion-exchange resins the pore stability is best when the material is in its lowest state of hydration. Generally, the collapse of pores is a reversible process. The collapsed material can in most cases be reswollen by the proper choice of solvent.

\section{INTRODUCTION}

Pore stability in crosslinked networks is of clear interest when the materials have to be applied in a dried state, or when a solvent has to be replaced by another one.

Previously, it was noticed that during the synthesis of porous networks, loss of porosity may occur. Millar and co-workers, ${ }^{1}$ in describing the preparation of toluene-modified polymer networks, reported the collapse of the network upon eventual removal of the solvent. A study done by Kun and Kunin ${ }^{2}$ showed that during the formation of styrene-divinylbenzene copolymers in the presence of a nonsolvating diluent, collapse will occur upon removal of that diluent.

In a previous report we described the formation of porosity in macromolecular networks as a function of the organic compounds present during the suspension polymerization. ${ }^{3}$ In the synthesis of the materials, collapse sometimes occurred when these materials were treated with solvating agents for reasons of purification.

Pore-structure investigation of porous ion-exchange resins was carried out by Kun and Kunin. ${ }^{4}$ Their study of the effect of hydration on the pore struc- 
ture is of special interest for this report. Briefly summarized, ref. 4 suggests the first step to be hydration of the nonporous gel phase, which is followed by filling of the porous phase either hydraulically or by capillary condensation.

For an investigation of the pore stability, we used the reverse treatment, i.e., dehydration of the porous ion-exchange resins and determination of the dehydration effect on the pore structure. This effect can be measured quantitatively by mercury penetrometry, ${ }^{4}$ or by studying the volume of the beads during the dehydration procedure as a function of the amount of water lost. It is demonstrated that loss of porosity may occur with the hydrophobic matrices as well as with the hydrophilic ion-exchange resins.

\section{EXPERIMENTAL}

\section{Styrene-Divinylbenzene Copolymer Matrices}

The authors have recently described the synthesis and the pore distribution of the matrices in the Journal of Applied Polymer Science (see ref. 3).

\section{Ion-Exchange Resins}

Weak anion exchangers. We prepared matrices according to the data given in Table IA and activated them by chloromethylation and amination with dimethylamine. We also examined some commercial types.

Strong cation exchangers. We prepared the matrices by sulfonation according to Table IB.

TABLE IA

Weakly Basic Anion Exchange Resins

\begin{tabular}{ccccccc}
\hline Experiment & DVB, $\%$ & $\begin{array}{c}\text { Heptane, } \\
\%\end{array}$ & $\begin{array}{c}\text { Toluene, } \\
\%\end{array}$ & $\begin{array}{c}\text { Type } \\
\text { Matrix }\end{array}$ & $\begin{array}{c}\rho_{0}, \\
\left(\mathrm{~g} / \mathrm{cm}^{3}\right)\end{array}$ & $\begin{array}{c}\text { Ion-exchange } \\
\text { capacity, } \\
\text { meg/g }\end{array}$ \\
\hline 08 & 10 & 65 & - & PP & 0.67 & - \\
09 & 10 & 60 & 20 & PPS & 0.72 & 4.7 \\
10 & 15 & 70 & - & PP & 0.55 & 3.8 \\
11 & 15 & 83 & 23 & PPS & 0.67 & 4.4 \\
\hline
\end{tabular}

TABLE IB

Strongly Acidic Cation-Exchange Resins ${ }^{\mathrm{a}}$

\begin{tabular}{ccccccc}
\hline $\begin{array}{c}\text { Experi- } \\
\text { ment }\end{array}$ & DVB, \% & $\begin{array}{c}\text { Heptane, } \\
\%\end{array}$ & Toluene & $\begin{array}{c}\text { Type } \\
\text { Matrix }\end{array}$ & $\begin{array}{c}\rho_{0}, \\
\left(\mathrm{~g} / \mathrm{cm}^{3}\right)\end{array}$ & $\begin{array}{c}\text { Ion-exchange } \\
\text { capacity, } \\
\text { meq/g }\end{array}$ \\
\hline 12 & 16 & - & - & PM & 0.85 & $5.2^{\mathbf{b}}$ \\
13 & 15 & 100 & - & PP & 0.40 & 3.1 \\
14 & 25 & 40 & - & PP & 0.71 & 4.4 \\
15 & 35 & 35 & - & PP & 0.68 & 3.9 \\
16 & 45 & 30 & - & PP & 0.71 & 3.4 \\
\hline
\end{tabular}

a See also Fig. 5 , which gives three types of curves relating volume with respect to weight loss: (i) concave type (stable porosity); (ii) linear type; (iii) convex type (collapsing pores on drying).

b IMAC C16P; 15\% linear polymer extracted. 


\section{Methods of Determining Pore Stability}

The apparent densities were measured in a calibrated tube. The surface areas were obtained by nitrogen adsorption-desorption isotherms using the Brunauer, Emmet, and Teller (BET) method. ${ }^{5}$

\section{RESULTS AND DISCUSSION}

\section{Hydrophobic Matrices}

Beads of porous matrices containing $25 \%$ of divinylbenzene (DVB) were dispersed in a good solvating agent, such as dichloromethane (DCM), and the solvent was removed by evaporation to dryness (Table IIA, experiments $01-$ 3). After this procedure the apparent densities were measured and showed an increase caused by loss of porosity. Electron micrographs did not show a difference between collapsed and noncollapsed matrices. Obviously, the micropores ( $<50 \AA$ ), which cannot be observed by scanning electron microscopy, collapse. This is demonstrated by the values of the internal surface of experiments $01-03$, in view of the fact that micropores contribute mainly to the internal surface.

We found the collapse to be a reversible process and observed the network to re-expand to its earlier state upon addition of the former solvating agent. It attained about the original apparent density when the solvent was replaced by a less solvating one such as acetone or ethanol, followed by evaporation to dryness. From these experiments we conclude: In a macromolecular network, pores can collapse as a consequence of cohesion when the solvated agglomerations of the polymer chains are approaching each other by loss of solvent.

This process can be counteracted by:

1. A decreased interaction between polymer chains and the fluid, which can be attained by

TABLE IIA

Collapse of Pores in Hydrophobic Networks ${ }^{a}$

\begin{tabular}{|c|c|c|c|c|c|c|c|}
\hline \multirow[b]{2}{*}{$\begin{array}{l}\text { Experi- } \\
\text { ment }\end{array}$} & \multirow[b]{2}{*}{$\begin{array}{l}\text { DVB, } \\
\%\end{array}$} & \multirow[b]{2}{*}{$\begin{array}{l}\rho_{0}, \text { Orig- } \\
\text { inal }\end{array}$} & \multirow{2}{*}{$\begin{array}{l}\rho_{0} \text { Dried } \\
\text { after } \\
\text { solvation }\end{array}$} & \multicolumn{2}{|c|}{$\mathrm{S}_{\mathrm{BET}}$} & \multirow{2}{*}{\multicolumn{2}{|c|}{$\begin{array}{c}\text { After re-expansion and } \\
\text { drying }\end{array}$}} \\
\hline & & & & original & $\begin{array}{l}\text { col- } \\
\text { lapsed }\end{array}$ & & \\
\hline & & & & & & $\rho_{0}$ & $\begin{array}{l}\text { re-expansion } \\
\text { solvent(s) }\end{array}$ \\
\hline 01 & 25 & 0.60 & 0.89 & 172 & 15 & $\begin{array}{l}0.65 \\
0.63\end{array}$ & $\begin{array}{l}\text { benzene } \\
\text { DCM + acetone }\end{array}$ \\
\hline 02 & 25 & 0.68 & 0.90 & - & - & $\begin{array}{l}0.68 \\
0.66\end{array}$ & $\begin{array}{l}\text { toluene } \\
\text { DCM + acetone }\end{array}$ \\
\hline 03 & 25 & 0.53 & 0.81 & 195 & 36 & 0.60 & CMA \\
\hline
\end{tabular}

a Abbreviations used:

DVB = divinylbenzene

DCM = dichloromethane

CMA = chloromethyl ether

$\rho_{0} \quad=$ apparent density

$\mathbf{S}_{\mathrm{BET}}=$ internal surface 
a. Substituting the solvent for a less solvating one.

b. A high concentration of DVB in the network; this will thus result in a restriction of the mobility of the polymer chains.

2. The presence of large pores. These prevent the agglomerations from contacting each other. Large pores can be formed by the addition of a high concentration of nonsolvent (PP-type matrix) and linear polymer (PM-type) to the polymerizing mixture or by a combination of both (PMP-type). ${ }^{3}$

The counteractions mentioned are demonstrated in Table IIB; see experiments 04-05 (high DVB\%) and experiments 06-07 (large pores).

\section{Hydrophilic Matrices}

The introduction of ionic functions like:

$-\mathrm{NR}_{2} \mathrm{HX}$ (weakly basic)

$-\mathrm{NR}_{3} \mathrm{X}$ (strongly basic)

$-\mathrm{SO}_{3} \mathrm{H}$ (strongly acidic)

into the styrene-divinylbenzene matrices changes the originally hydrophobic material into a hydrophilic one. The ion-exchange resins therefore generally contain $30-65 \%$ of water by weight. The behavior of these resins during drying is dependent on:

1. The original porosity of hydrophobic matrix.

2. The type and amount of attached active functions.

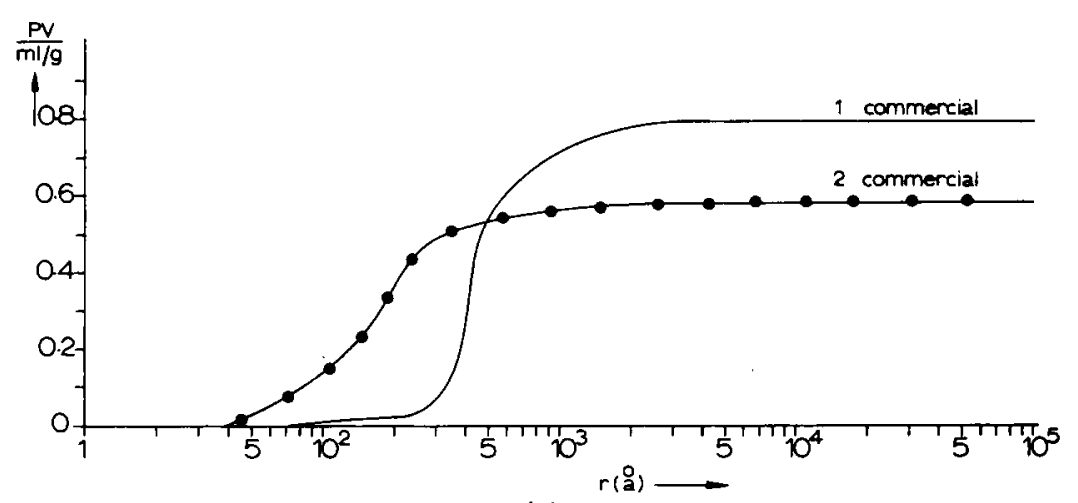

(a)

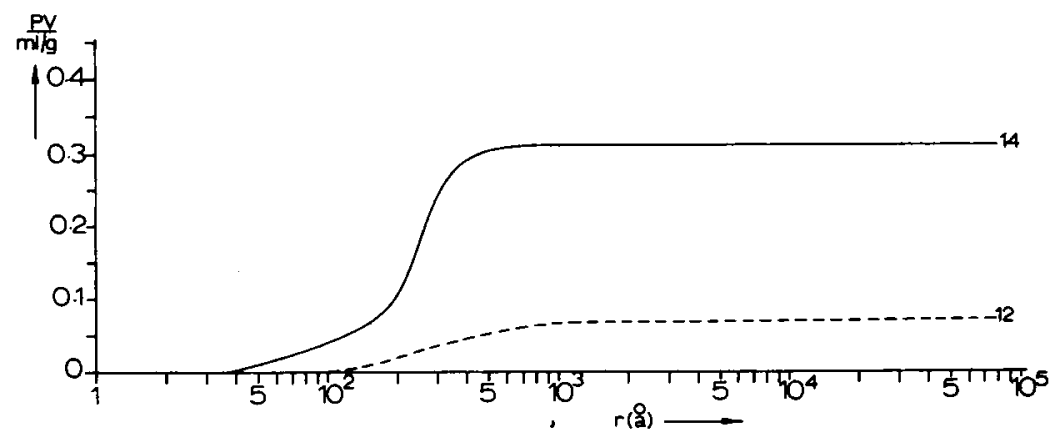

(b)

Fig. 1. (a) Pore spectrum of commercial samples 1 and 2, (b) Pore spectrum of Imac C16P (expt 12) and PP-type resin (expt 14). 
If the material regards a weak electrolyte, there is also a state of strong solvation and less solvation: e.g., weakly basic anion exchangers are strongly swollen at low $\mathrm{pH}$, weakly acidic cation exchangers, at a high $\mathrm{pH}$.

One can expect to find two stages during dehydration:

1. Evaporation of the water from the pores. The solvation water is not involved. If the porous network can stand the process, the volume of the microspheres $^{3}$ and consequently of the ion-exchange beads is not essentially affected. However, if the small pores within the microspheres are collapsing, the network is shrinking.

2. Evaporation of the solvation water in the gel phase. This is always accompanied by a shrinkage of the gel volume (resin volume). The dehydration curve gives us a tool to determine by a simple method, whether an ionexchange resin has a reasonable pore stability or not.

From the drying curves we can determine:

1. The total pore volume, i.e., the amount by weight (and volume) of the water to be removed without essential loss of total bead volume. This is represented by the horizonial part of the curve.

2. The amount of hydration water to be removed from the gel phase of the beads, after the preceding removal of water from the pores. This is represented by the sloped part of the curve. The length of the horizontal part of the drying curve can be foreseen when one is measuring the mercury porosity of the original matrix.

In relatively pore-stable ion-exchange resins, the mercury porosity of the dried exchangers themselves can, of course, be measured. We prepared ionexchange resins from matrices of known porosity and examined their behavior during drying. We also examined some commercial materials (Figs. 1a and $1 \mathrm{~b}$ ) and correlated their drying curves with the porosity in the dried and partly collapsed state.

\section{Weakly Basic Anion-Exchange Resins}

The experiments are shown in Table IA and in Figures 2, 3, and 4. Of the two commercial samples of anion-exchange resins (Fig. 4), sample 1 has a large pore volume as well as large pores, as shown in Figure 1a which represents the integral porosity of the two samples.

When dried in the hydrogen chloride state sample 2 directly starts to collapse, whereas sample 1 shows the typical drying curve of a pore-stable mate-

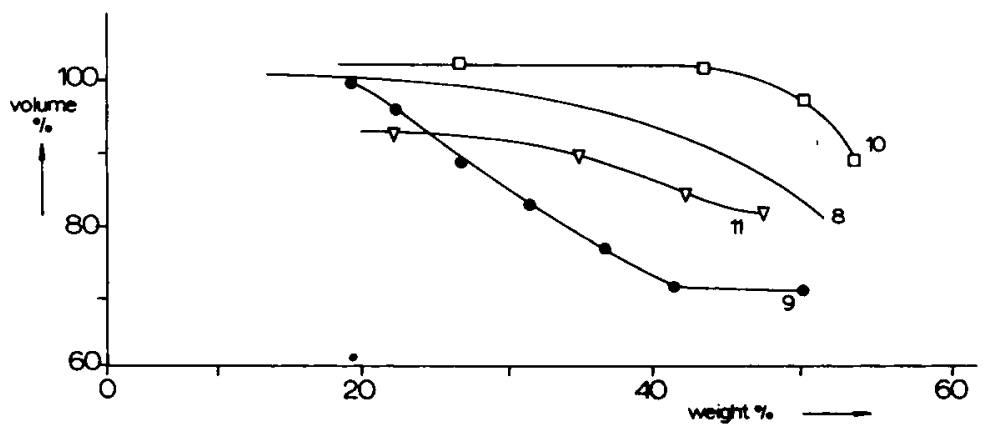

Fig. 2. Dehydration curve of weakly basic anion-exchange resins in base form (expt 08-11) evaporation at $20^{\circ} \mathrm{C}$ up to $40 \%$ weight decrease; above $40 \%$, evaporation at $100^{\circ} \mathrm{C}$. 


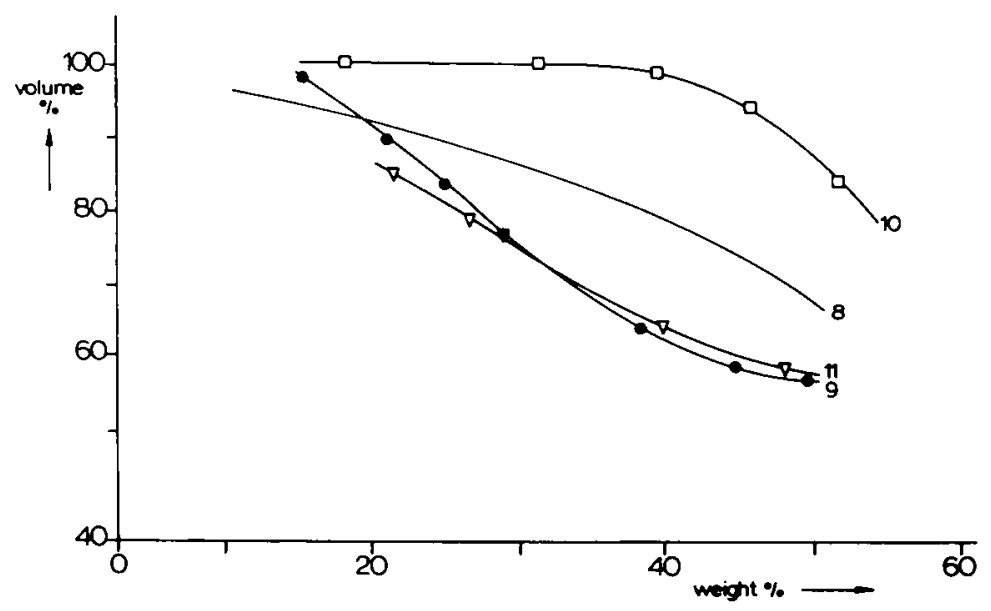

Fig. 3. Dehydration curve of weakly basic anion-exchange resins in hydrogen chloride form (expt 08-11).

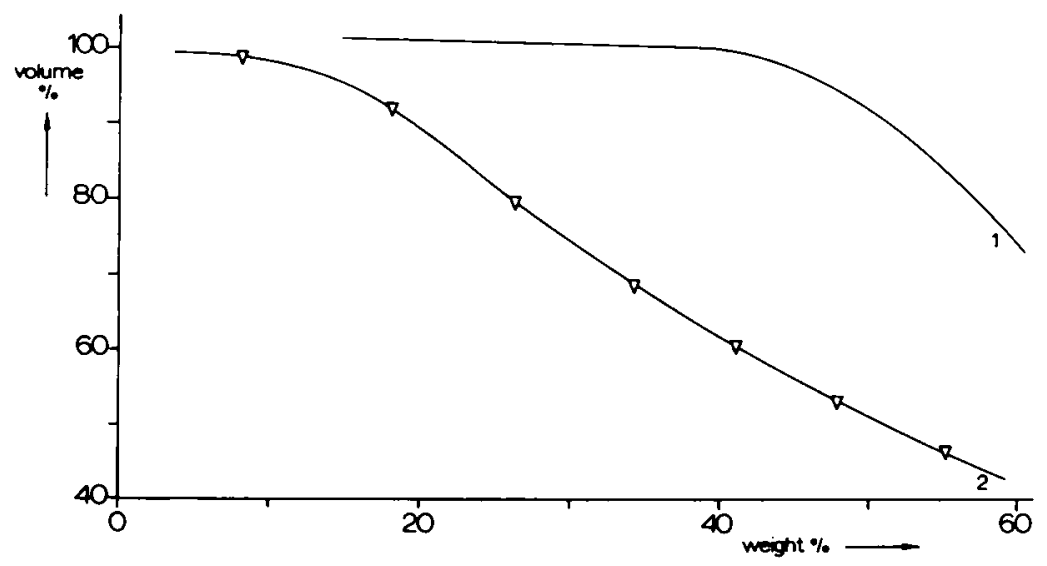

Fig. 4. Dehydration curve of commercial weakly basic anion-exchange resing 1 and 2; dried in hydrogen chloride form.

rial (Fig. 4). Of the four samples prepared from well-known matrices, only sample 10 represents the pore-stable type when dried in both forms (Figs. 2 and 3 ). This sample (PP-type) has a high DVB content as well as a high porosity, reflected by $\rho_{0}=0.55$ (Table IA).

In our preceding paper ${ }^{3}$ we show that when solvent is added to the precipitation polymerization in heptane, the resulting PPS-matrix has a lower pore volume and smaller pores. The pore instability of sample 9 in both states (OH- and $\mathrm{HCl}-)$ is thus not surprising. Samples 8 and 11 show an intermediate behavior with a logical tendency to less-collapse in the less hydrated $\mathrm{OH}$ state.

\section{Strongly Acidic Cation-Exchange Resins}

The strongly solvated sulfonic acid groups in the polymer network will favor the ease with which pores collapse upon drying. Large pores will contribute to pore stability again (see Table IIB and Fig. 5). Thus, a high-capac- 
TABLE IIB

Pore Stability in Hydrophobic Networks ${ }^{a}$

\begin{tabular}{|c|c|c|c|c|c|c|}
\hline \multirow[b]{2}{*}{$\begin{array}{l}\text { Experi- } \\
\text { ment }\end{array}$} & \multirow[b]{2}{*}{ DVB, $\%$} & \multirow[b]{2}{*}{$\begin{array}{c}\rho_{0} \text { Orig- } \\
\text { inal }\end{array}$} & \multirow{2}{*}{$\begin{array}{l}\rho_{0} \text { Dried } \\
\quad \text { after } \\
\text { solvation }\end{array}$} & \multicolumn{2}{|c|}{$\mathbf{S}_{\mathbf{B E T}}$} & \multirow[b]{2}{*}{ Remarks } \\
\hline & & & & original & $\begin{array}{c}\text { after } \\
\text { solvation }\end{array}$ & \\
\hline 04 & $\begin{array}{c}\text { Amberlite } \\
\text { XAD-4 }\end{array}$ & 0.52 & 0.52 & 800 & 800 & - \\
\hline 05 & 55 & 0.48 & 0.50 & 421 & 400 & - \\
\hline 06 & 25 & 0.50 & 0.51 & 一 & - & PMP-type \\
\hline 07 & 18 & 0.63 & 0.63 & - & - & PMS-type \\
\hline
\end{tabular}

a Abbreviations used:

DVB = divinylbenzene

$\mathrm{DCM}=$ dichloromethane

$\mathrm{CMA}=$ chloromethyl ether

$\rho_{0} \quad=$ apparent density

$\mathrm{S}_{\mathrm{BET}}=$ internal surface

ity exchanger of only $15 \%$ pore volume, like PM-type Imac C16P (sample 12), having a pore radius varying from $150-1500 \AA$ (Fig. 1b), shows the convex curve of pore-stable drying.

The same is found for a high-porosity laboratory sample of the PP-type having large pores, e.g., sample 13. Notwithstanding much higher DVB contents and consequently lower degrees of activation, the porous samples 14,15 , and 16 show pore instability caused by the $50-300 \AA$ pore diameter present in their PP-matrix.

\section{CONCLUSIONS}

1. In a macromolecular network, pores can collapse as a consequence of cohesion when the solvated agglomerations of the polymer chains are approaching each other by loss of solvent.

2. It is shown that also with ion-exchange resins, the same principles ruling pore stability are encountered as were found in their matrices. Ion-exchange materials prepared from matrices having sufficient DVB content and rela-

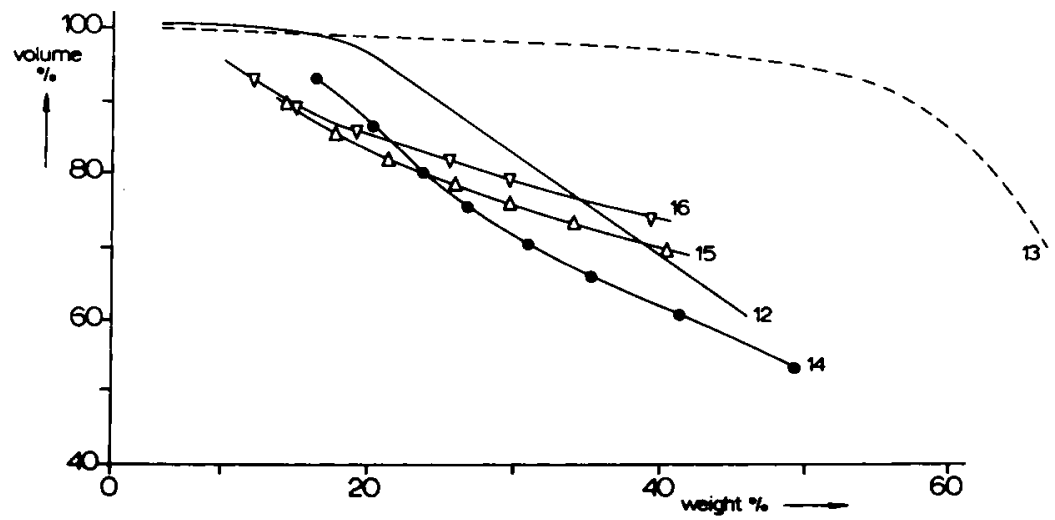

Fig. 5. Dehydration curve of strongly acidic cation-exchange resins (expt 12-16). See also data, Table IB. 
tively wide pores, mostly connected with a high pore volume, retain their volume during removal of solvent better than types having lower pore volumes and smaller pores.

The new factor compared to the hydrophobic matrices is only the chemical character. It is seen at the strongly acidic cation exchanger that it is very difficult to make pore-stable material of the macroporous PP-type. This is because of the enormous solvating power of the $\mathrm{SO}_{3} \mathrm{H}$-group.

\section{References}

1. J. R. Millar, D. G. Smith, W. E. Marr, and T. R. E. Kressman, J. Chem. Soc., 2779 (1963).

2. K. A. Kun and R. Kunin, J. Polym. Sci A-1, 6, 2689 (1968).

3. W. L. Sederel and G. J. de Jong, J. Appl. Polym. Sci., 17, 2835 (1973).

4. K. A. Kun and R. Kunin, J. Polym. Sci. C, 16, 1457 (1967).

5. S. Brunauer, Physical Adsorption, vol. 1, Princeton Univ. Press, Princeton, N. J., 1943.

Received November 22, 1974 